\title{
Estimating DSGE Models with Zero Interest Rate Policy ${ }^{\text {出 }}$
}

\author{
Mariano Kulish ${ }^{\mathrm{a}, *}$, James Morley ${ }^{\mathrm{a}}$, Tim Robinson ${ }^{\mathrm{b}}$ \\ ${ }^{a}$ School of Economics, UNSW Business School, UNSW \\ ${ }^{b}$ Melbourne Institute of Applied Economic and Social Research, University of Melbourne
}

\begin{abstract}
We propose estimating DSGE models in which the central bank fixes the policy rate for an extended period of time and apply our approach to estimate expected durations of the Federal Reserve's zero interest rate policy since 2009. We find a large increase in expected duration in 2011 with the move to calendarbased guidance and a decrease in 2013 with the 'Taper tantrum'. These changes are identified by the influence of expected duration on output, inflation and interest rates at longer maturities. The structural model measures the severity of the zero lower bound constraint and the effects of unconventional policy.
\end{abstract}

Keywords: Zero lower bound, forward guidance, Bayesian estimation.

JEL codes: E52, E58

\section{Introduction}

To combat the recent financial crisis and the resulting economic downturn, the Federal Reserve and many other central banks pushed their policy interest rates close to the zero lower bound and turned, among other unconventional policies, to forward guidance. Forward guidance refers to announcements about the future path of the policy rate. This communications policy has received considerable attention in the press and the academic literature. In particular, while some central banks had previously communicated about the direction or timing of future policy rates for the purpose of transparency, the recent announcements have been interpreted as explicit attempts to influence expectations so as to increase the current degree of monetary policy accommodation (see Woodford (2012)).

There is a good argument in theory as to why such forward guidance can lessen the contractionary impact of the zero lower bound. In forward-looking models the current stance of monetary policy depends on the expected path of the nominal interest rate and therefore forward guidance can, in principle, stimulate aggregate demand to the extent it lowers private agents' forecasts of future nominal interest rates. A credible commitment to maintain the policy rate at zero for longer than would have otherwise been implied by the zero bound itself therefore represents an additional channel of monetary stimulus. Eggertsson and Woodford (2003), Jung et al. (2005) and more recently Werning (2012) all make this point: monetary policy can stimulate the economy by creating the right kind of expectations about how monetary policy will be conducted after the zero lower bound constraint ceases to bind.

\footnotetext{
We wish to thank the editors Ricardo Reis, Giorgio Primiceri and an anonymous referee for detailed comments that have helped us improve the paper. We would also like to thank our discussant at the 2013 RBNZ Conference, Andrea Tambalotti, for valuable suggestions at an earlier stage of the work. For useful discussions we thank Efrem Castelnuovo, Han Chen, Marco Del Negro, Marc Giannoni, Callum Jones, Giovanni Pellegrino, Bruce Preston, Sarantis Tsiaplias and seminar participants at Deakin University, Monash University, the University of Melbourne, ESAM Hobart 2014, Econometrics Society World Congress, 2015, the Federal Reserve Banks of Atlanta and New York, the Dynare Conference at the National Bank of Belgium, Banco Central do Brasil, and the Sydney Macroeconomics Reading Group. Stephen Elias provided valuable for research assistance. This research was supported by ARC DP 160102654. The usual disclaimers apply.

${ }^{*}$ Corresponding Author: School of Economics, UNSW Business School, Gate 2, High Street, UNSW Sydney, NSW, 2052, Australia, m.kulish@unsw.edu.au, TEL.: +61293853670
} 
In this paper, we build on Kulish and Pagan (2017) to construct the likelihood function for a DSGE model in which monetary policy switches at the zero lower bound from following a standard Taylor-type rule to the policy rate being fixed at zero for an extended period of time, essentially along the lines of a strict calendar-based forward guidance. In particular, Bayesian methods allow us to estimate for the sample period of 1983Q1-2014Q2 both the structural parameters of the Smets and Wouters (2007) model and the expected duration of the zero interest rate policy in each quarter since 2009Q1. To help with identification given the loss of variation of the policy rate at the zero lower bound, we augment the model with information from the yield curve.

The joint estimation of structural parameters and sequence of expected durations in the context of a DSGE model provides a way to address the zero lower bound and constitutes the key contribution of our paper. In particular, zero interest rate policy was in place in the United States for more than seven years. This raises a challenge in estimation that will persist into the future: even if the zero lower bound were to never bind again, future samples of macroeconomic data will have a long spell of zero interest rates. We propose a simple way by which DSGE models can be estimated accounting for the effects of the zero lower bound which is not computationally intensive and can readily be applied to medium and large-scale models. ${ }^{1}$

In a related and contemporaneous strand of literature, a Markov switching (MS) specification has been used by Chen (2014) and by Bianchi and Melosi (2017) to solve and estimate models with a period of zero interest rate policy. An MS specification has the advantage of allowing the period of zero interest rates to recur with some probability. However, a weakness is that the transition probabilities are constant, which implies that so too is the expected duration throughout the fixed-rate regime, and these probabilities may be difficult to identify given the rarity of regime switches in the data. ${ }^{2}$ The advantage of our approach, in addition to its relative simplicity, is its flexibility as it allows agents to hold a different expected duration in each quarter of the zero interest rate policy. Such a specification is empirically desirable given the evidence from survey measures and financial markets that the expected duration has indeed varied considerably since 2009 (see Swanson and Williams (2014)) and given that an aim of forward guidance is to influence these expectations. Meanwhile, other authors, like Boneva et al. (2016), Gust et al. (Forthcoming) and Fernández-Villaverde et al. (2015) have argued that linearized solutions are inaccurate at the zero lower bound. It is important to note, however, that our piecewise linear combination of regimes, following Cagliarini and Kulish (2013), produces a highly non-linear approximate solution. Guerrieri and Iacoviello (2015) and Jones (2015) show that the piecewise linear solution provides a good approximation to the full non-linear solution. A careful comparison between our approach and the occasionally binding constraint method follows in Section 2.

In our analysis, the data speak through the lens of a model in which the central bank's forward guidance is explicitly calendar-based. During a fixed-rate regime, agents form expectations based on the assumption that the central bank will unconditionally keep the policy rate at zero for a certain number of quarters in the future, after which it will revert back to its temporarily abandoned Taylor rule. However, in the case of a more threshold-based forward guidance, such as was pursued by the FOMC since December 2012, our approach still provides a measure of what such state-contingent guidance implies about the expected duration of a fixed-rate regime.

In addition to incorporating information from the yield curve, we achieve identification of the sequence of expected durations of the zero interest rate policy because variation in expected duration gives rise to distinct dynamics of the aggregate variables, because the subsample prior to the zero lower bound helps identify competing sources of exogenous variation and because there are no unanticipated shocks to the policy rate in the fixed-rate regime. It is well known that in models with rational expectations, forward guidance is powerful in the sense that it can generate very large responses of aggregate variables, a

\footnotetext{
${ }^{1}$ Estimation of a fully non-linear model is numerically much more complex, as acknowledged by Gust et al. (Forthcoming) who set the measurement error variance to 25 per cent of the variance of observed variables to stabilize the particle filter used for such estimation.

${ }^{2}$ Although one could, in principle, consider time-variation of the transition probabilities due to exogenous or predetermined variables, this would seem to be even more difficult to identify given the rarity of regime switches and in light of the acknowledgment made by Baele et al. (2015) that estimation of a stylized New Keynesian model with Markov switching is a numerically difficult and complex task.
} 
phenomenon identified by Carlstrom et al. (2015) which Del Negro et al. (2012) call the 'forward guidance puzzle'. For the purposes of econometric identification, however, this sensitivity of aggregate variables to forward guidance turns out to be useful in pinning down the sequence of expected durations in estimation. At the same time, it is worthwhile noting that an absence of 'unreasonably large' fluctuations in the data does not necessarily imply short expected durations. This is because, as discussed below in the context of the Smets-Wouters model, the effect of a longer expected duration can be offset by other factors such as negative risk premium shocks.

The rest of the paper is structured as follows. Section 2 discusses the model and methods used to solve and estimate it. Section 3 describes the data and our priors. Section 4 reports the main estimation results. Section 5 uses the estimated model to analyze monetary policy at the zero lower bound. Section 6 concludes.

\section{Model and Methods}

We consider the Smets and Wouters (2007) model in order to illustrate our proposed approach to estimating DSGE models with zero interest rate policy in a well-understood environment. However, to help address the econometric implications of the loss of variation in the policy rate at the zero lower bound, the model is extended to incorporate information from the yield curve into the model in a manner similar to Graeve et al. (2009). Because the details of the model are well-known, only the new equations related to the incorporation of the yield curve and the methods for solving and estimating the model given a fixed-rate regime are presented here. A brief description of the rest of the model and the remaining equations are provided in the on-line appendix.

\subsection{Incorporation of the Yield Curve}

Although the original Smets and Wouters (2007) model only explicitly includes one period bonds, we incorporate information from the yield curve to aid with identification at the zero lower bound. In particular, under the expectations hypothesis, yields on long bonds will reflect agents' beliefs about the future path of the policy rate:

$$
\hat{r}_{j, t}=\frac{1}{j} \mathbb{E}_{t}\left(\hat{r}_{t}+\hat{r}_{t+1}+\cdots+\hat{r}_{t+j-1}\right) \text { for } j=2,3, \ldots, m
$$

where $\hat{r}_{j, t}$ denotes the $\log$ deviation of the yield on a $j$-period bond from steady-state. Consequently, longer yields may be incorporated by augmenting the model with equation (1) for various maturities.

It is well-known that the strict version of the expectations hypothesis in equation (1) does not perform well empirically (e.g. Campbell and Shiller (1991)), but even if it did, it would be necessary to add shocks for purposes of estimation. In particular, motivated by Graeve et al. (2009), we relate the model-implied yields, $\hat{r}_{j, t}$, to their observed counterparts, $r_{j, t}$, as follows:

$$
\begin{aligned}
r_{j, t} & =\hat{r}_{j, t}+r+c_{j}+\eta_{t}+\varepsilon_{j, t} \text { for } j=2,3, \ldots, m \\
\eta_{t} & =\rho_{\eta} \eta_{t-1}+\varepsilon_{\eta, t},
\end{aligned}
$$

where $r$ is the steady state of the one-period nominal interest rate and there are two components to the term premia: first, $c_{j}$ is a maturity-specific time-invariant component, and consequently $r+c_{j}$ is the steady state of a yield with $j$ periods to maturity. Second, there is a time-varying component; this is composed of a persistent shock, $\eta_{t}$, that follows a first-order autoregressive process and is common to all observed maturities, and an idiosyncratic, i.i.d. maturity-specific shock, $\varepsilon_{j, t}$.

Our specification with term premia parameters and shocks provides a convenient approach to incorporating information from the yield curve in the estimation of the Smets and Wouters (2007) model. In particular, a more structural approach that priced all bonds using an arbitrage-free stochastic discounting relationship would likely have deleterious effects on the macroeconomic fit of the model, without necessarily generating sufficient variation in term premia to address the empirical failure of the expectations hypothesis (see Rudebusch and Swanson (2008)). 


\subsection{Solution Method}

To solve for equilibria in the presence of a fixed-rate regime, we use a special case of the solution of Kulish and Pagan (2017) for forward-looking models with anticipated structural change.

For illustration, consider a sample of $T$ time series observations that includes an extended period in which the policy rate is fixed at the zero lower bound. For notational convenience in presenting the solution, the date at which the policy rate hits the zero lower bound is normalized to be $t=1$. Figure 1 presents a zero interest rate policy that lasts for $d$ periods, with conventional policy resuming out of sample, although it could resume in sample instead.

In the form of Binder and Pesaran (1995), the system of linearized equations for the Smets and Wouters (2007) model can be written as

$$
y_{t}=J+A y_{t-1}+B \mathbb{E}_{t} y_{t+1}+D \varepsilon_{t},
$$

where $y_{t}$ is an $n \times 1$ vector of state and jump variables and with no loss of generality $\varepsilon_{t}$ is a $l \times 1$ vector of white noise shocks; the matrices $J, A, B$ and $D$ are of conformable dimensions. Prior to the zero lower bound, the economy follows equation (4) and the standard rational expectations solution applies. If the solution exists and is unique, then $y_{t}$ follows the VAR process

$$
y_{t}=C+Q y_{t-1}+G \varepsilon_{t} .
$$

When the zero lower bound hits at $t=1$, the central bank sets its policy rate to zero, $\hat{r}_{t}=-r$, and communicates a plan to revert back to the conventional policy rule at a later date, $t=d^{e}+1$. Assuming the central bank communications are credible, the expected duration of the fixed-rate regime in period $t=1$ will be given by $d^{e}$. During this fixed-rate regime, the structural equations are given by

$$
y_{t}=\bar{J}+\bar{A} y_{t-1}+\bar{B} \mathbb{E}_{t} y_{t+1}+\bar{D} \varepsilon_{t},
$$

and monetary policy now follows $\hat{r}_{t}=-r$. Such a monetary policy rule that fixes the nominal interest rate would give rise to indeterminacy if agents expected the rule to be implemented indefinitely. However, if monetary policy is expected to adopt a rule consistent with a unique equilibrium after $d^{e}$, then, as shown in Cagliarini and Kulish (2013), a rule like $\hat{r}_{t}=-r$ can be temporarily consistent with a unique equilibrium as well.

In solving for $y_{t}$ in the fixed-rate regime, first suppose for simplicity that monetary policy actually does revert back to conventional policy as planned at $t=d^{e}$, so $d^{e}=d$. For periods $t=1,2, \ldots, d$, the solution for $y_{t}$ would follow the time-varying coefficient VAR process

$$
y_{t}=C_{t}+Q_{t} y_{t-1}+G_{t} \varepsilon_{t}
$$

which implies that

$$
\mathbb{E}_{t} y_{t+1}=C_{t+1}+Q_{t+1} y_{t}
$$

Using equations (8) and (6), it is possible to establish via undetermined coefficients that

$$
\begin{aligned}
\left(I-\bar{B} Q_{t+1}\right)^{-1}\left(\bar{J}+\bar{B} C_{t+1}\right) & =C_{t} \\
\left(I-\bar{B} Q_{t+1}\right)^{-1} \bar{A} & =Q_{t} \\
\left(I-\bar{B} Q_{t+1}\right)^{-1} \bar{D} & =G_{t} .
\end{aligned}
$$

Starting from the solution to the terminal regime, $C_{d+1}=C$ and $Q_{d+1}=Q$, equation (10) determines via backward recursion the sequence $\left\{Q_{t}\right\}_{t=1}^{d}$. Then, with the sequence $\left\{Q_{t}\right\}_{t=1}^{d}$ in hand, equation (11) yields the sequence $\left\{G_{t}\right\}_{t=1}^{d}$, and equation (9) pins down $\left\{C_{t}\right\}_{t=1}^{d}$. Note that, in the sequence $\left\{Q_{1}, Q_{2}, \ldots, Q_{d}\right\}$, the matrix associated with an expected duration of $d$ periods is $Q_{1}$, the matrix associated with an expected duration of $d-1$ periods is $Q_{2}$ and so on until $Q_{d}$ for an expected duration of 1 period, and likewise for $\left\{G_{t}\right\}_{t=1}^{d}$ and $\left\{C_{t}\right\}_{t=1}^{d}$.

More generally, now suppose that the central bank re-evaluates the timing of the return to conven- 
tional policy every period and announces its plans as they progress. If the plans change over time and, again, if the communications are regarded as credible by agents, then the sequence of reduced-form matrices would evolve according to the expected duration in each period. For example, if in every period monetary policy were to announce and agents were to expect zero interest rates to last for $d^{e}$ periods, then the resulting sequence of reduced form matrices for $Q_{t}$ would simply be $\left\{Q_{1}, Q_{1}, \ldots, Q_{1}\right\}$. In general, given $\left\{C_{t}\right\}_{t=1}^{\bar{d}},\left\{Q_{t}\right\}_{t=1}^{\bar{d}}$ and $\left\{G_{t}\right\}_{t=1}^{\bar{d}}$ for an upper bound $\bar{d}$ such that $d_{t}^{e} \leq \bar{d}$, the reduced form matrices that prevail in a given period $t$ will be $C_{\bar{d}-d_{t}^{e}+1}, Q_{\bar{d}-d_{t}^{e}+1}$ and $G_{\bar{d}-d_{t}^{e}+1}$.

In work that is contemporaneous and independent to this analysis, Guerrieri and Iacoviello (2015) propose a way of solving models with occasionally binding constraints. Their solution may be viewed an iterative application of the solution of Cagliarini and Kulish (2013) where a 'guess and verify' step is used, as shown by Jones (2015), to find the expected duration of the binding regime which is consistent with the state of the economy. Consequently, once this expected duration is found, the reduced form matrices associated with that duration are exactly the same as computed above. Guerrieri and Iacoviello (2015) do not consider estimation with data from the period of zero interest rates. But if one intended to do so, then the occasionally binding constraint approach can be interpreted as imposing a restriction on the sequence of expected durations. Because an expected duration would be completely determined by past and present shocks, it could not be treated, as we do, as a free parameter in estimation.

The restriction imposed by the constraint on the sequence of expected durations, however, may or may not hold in the data. Our approach is free to choose the sequence which best fits the data, and so it could, in principle, be used to assess the extent to which that restriction holds. A possible drawback, however, is that a particular estimated expected duration may turn out to be shorter than what the constraint would have implied. ${ }^{3}$ But the main advantage of our approach is that it allows, but does not require, the expected duration of the zero interest rate policy to co-exist with a non-binding constraint. In particular, by allowing for the possibility of a non-binding constraint in estimation, our approach accommodates the optimal policy prescription and aim of forward guidance of prolonging the duration of the zero interest rate policy beyond the constraint ceasing to bind - i.e., the policy rate is to be held "lower for longer".

\subsection{Estimation}

We use Bayesian methods for estimation of the model, as is common in the DSGE literature (see An and Schorfheide (2007)). However, there are two modifications to the standard approach to accommodate the presence of a fixed-rate regime. First, it is necessary to allow the Kalman filter to handle missing observations related to the policy rate during the fixed-rate regime. Specifically, as the federal funds rate has no variance at the zero lower bound, it is removed as an observed variable to prevent the variancecovariance matrix of the one-step ahead predictions of the observables from becoming singular. ${ }^{4}$ Second, we jointly estimate two distinct sets of parameters: the structural parameters with continuous support (denoted $\theta$ hereafter) and the sequence of expected durations $\left\{d_{t}^{e}\right\}$ with discrete support (denoted simply by $\mathbf{d}$ hereafter). Because $\mathbf{d}$ can take on only integer values, it needs to be treated differently than $\theta$ in posterior simulation.

\subsubsection{State-space representation}

Before the zero lower bound, the model variables, $y_{t}$, follow the reduced-form solution from equation (5) and are related to the observed variables, $z_{t}$, via the measurement equation

$$
z_{t}=H y_{t}+v_{t}
$$

Then, for the fixed-rate regime, there is a new vector of observables, $\bar{z}_{t} \equiv W z_{t}$, where $W$ is an $\left(n_{z}-1\right) \times n_{z}$ matrix that selects a subset of the observed variables in $z_{t}$. Specifically, the federal funds rate is removed

\footnotetext{
${ }^{3}$ The Markov switching formulations of Bianchi and Melosi (2017), Binning and Maih (2016) and Chen (2014) that consider exogenous transition probabilities can also imply expected durations which are less than what the zero lower bound constraint would have implied.

${ }^{4}$ Alternatively, one could allow for measurement error in the observation equation of the federal funds rate. However, there is little variation of the federal funds rate throughout the zero lower bound period and we do not consider this variation to be a form of measurement error.
} 
from the set of observables. Defining $\bar{H} \equiv W H$ and $\bar{v}_{t} \equiv W v_{t}$, the model variables follow the reducedform solution from equation (7), where the sequence of reduced-form matrices, $\left\{C_{t}, Q_{t}, G_{t}\right\}_{t=1}^{d}$, is a function of the sequence of expected durations $\mathbf{d}$, and are related to the subset of the observables during the zero lower bound period by

$$
\bar{z}_{t}=\bar{H} y_{t}+\bar{v}_{t} .
$$

Although the formulation allows for measurement error, we set its variance to zero in estimation. Together, equations (5), (7), (12) and (13) provide a state space model to which the Kalman filter is applied to construct the likelihood, as described in the on-line appendix.

\subsubsection{The Sampler}

To sample from the joint posterior of the structural parameters and the sequence of expected durations of the zero lower bound, $p(\theta, \mathbf{d} \mid Z)$, where $Z \equiv\left\{z_{t}\right\}_{t=1}^{T}$ is the data, we use the Metropolis-Hastings algorithm. Due to the different nature of the structural parameters and the sequence of expected durations, they are drawn from two separate blocks of the sampler, although, to be clear, our sampler delivers draws from the joint posterior for all model parameters. ${ }^{5}$ The specific steps of the posterior sampler are described in the on-line appendix, but the key elements of the two blocks are summarized here.

The first block of the sampler is for the sequence of expected durations of the zero lower bound, $\mathbf{d}$. If the entire sequence of expected durations were updated at each iteration of the sampler, the acceptance rate would be extremely low. Therefore, motivated by the randomized blocking scheme developed for DSGE models in Chib and Ramamurthy (2010), we update only a subset of the durations at each iteration. The aim of random blocking is to reduce the autocorrelation of the draws. Specifically, we randomize both the number of expected durations in $\mathbf{d}$ to be updated, and which particular expected durations in $\mathbf{d}$ to update. This increases the acceptance rate considerably. For this block, we use an independent uniform proposal density.

The second block of the sampler is for the structural parameters. It follows a similar strategy to the block for $\mathbf{d}$ described above - i.e., we randomize over the number and which parameters to possibly update at each iteration. A difference, however, is that we use a random walk sampler. The proposal distribution for all of the structural parameters is a multivariate Student $t$ distribution with its scale matrix chosen using the inverse of Hessian at the mode of the pre-zero lower bound period. To obtain a proposal distribution for the block of parameters that are changing, we condition on the current values of the remaining parameters, which yields a multivariate Student $t$ distribution (see Ding (2016)). This approach is similar to that of Chib and Ramamurthy (2010), but is less computationally intensive as it does not require repeatedly re-estimating the Hessian of the conditional posterior.

In summary, a multi-block algorithm with random blocking within each block is used to construct draws from the joint posterior, $p(\theta, \mathbf{d} \mid Z){ }^{6}$

\section{Data and Priors}

\subsection{Data}

The data series used in estimation follow Smets and Wouters (2007): consumption, investment and output per capita growth, average hours worked, the federal funds rate, real wages and inflation. To these, yields at maturities of two and five years are added. The sample period is 1983Q1-2014Q2, with the onset of the zero lower bound occurring in 2009Q1. The details and plots of the data are available in the on-line appendix.

\footnotetext{
${ }^{5}$ To initialize the sampler and propose draws, we use an estimate of the mode and curvature of the posterior for the structural parameters. As the durations are integers, the mode and negative inverse Hessian for the posterior of the structural parameters are estimated on the subsample up to 2008Q4. However, results are robust to initializing the sampler using random starting values.

${ }^{6}$ Our code is available at https://sites.google.com/site/marianokulish/home/research.
} 


\subsection{Priors}

The joint prior for the model parameters is split into two independent priors, one for the structural parameters, $p(\theta)$, and one for the sequence of expected durations, $p(\mathbf{d})$. These are each discussed in turn.

The prior for the structural parameters, $p(\theta)$, is factorized into independent priors for each structural parameter, which are set following Smets and Wouters (2007), with the exception of some of the shock variances, which are adjusted to allow the model to capture the increased volatility post 2008, and the prior for trend growth, which is tightened at a slightly higher value. ${ }^{7}$ These priors, together with the posterior estimates discussed in the next section, are given in Table $1 .^{8}$

For the sequence of expected durations, we use an informative prior. In particular, the prior is constructed using two data sources which are not included in the observed variables, namely the Federal Reserve Bank of New York's Survey of Primary Dealers (hereafter Primary Dealers) and the Blue Chip Financial Forecasts (hereafter Blue Chip). These sources are also used in the zero lower bound studies of Bauer and Rudebusch (2016) and Swanson and Williams (2014).

The Primary Dealers survey provides a direct measure of expected duration, but is only available from 2011 onwards, and consequently we use the Blue Chip survey for the earlier period.

To construct a probability distribution from the Primary Dealers survey we use the average response in the last month of the quarter to the following question: "Of the possible outcomes below, please indicate the percent chance you attach to the timing of the first federal funds rate increase." Because the survey allows for an open-ended response (e.g., in the December 2012 survey respondents placed a probability of liftoff being 'in the first half of 2017 or later'), we allocated the remaining probability as follows: half was spread equally in the next half-year, and the remainder equally over the next year.

We use the Blue Chip survey for the period March 2009 to December 2010. Respondents were asked to forecast the federal funds rate over the next six quarters. This is a point forecast, in contrast to the probabilistic forecasts in the Primary Dealers survey. However, as the Blue Chip survey includes more than 40 respondents, we use the cross-sectional variation as a proxy for the distribution of probabilities. As the survey also allows for an open-ended response, the same rule is applied as with the Primary Dealers survey to allocate the remaining probability. ${ }^{9}$

The resulting density which summarizes the information on the sequence of expected durations from the surveys is shown in Figure 2. As in Swanson and Williams (2014), there is a noticeable increase in the median expected duration associated with the shift to calendar-based forward guidance in September of 2011. Note also that the survey data places non-negligible weight on long durations, namely durations between 3 and 4 years.

The prior for the sequence of expected durations, $p(\mathbf{d})$, is then constructed as an equally-weighted mixture of the distribution implied by the survey data and a uniform distribution over possible durations, where the maximum expected duration is set to 23 quarters as there is no probability in the survey measures beyond that duration. Results where the prior is either entirely based on the survey data or not at all are available in the on-line appendix. However, we deliberately consider a mixture distribution for the prior to allow mass on all durations in all periods so as to better assess the extent to which aggregate data and the model influence our inferences regarding the expected durations.

\footnotetext{
${ }^{7}$ In preliminary attempts to estimate the model including data from the zero lower bound period, we found that the original priors of Smets and Wouters (2007) led to implausibly low estimates of trend growth. This generated a discrepancy between the steady state of the model and the sample mean growth rates, which in turn led to very persistent shock processes. Because the proposal density is symmetric, these highly persistent processes led to very low acceptance rates in posterior simulation as explosive draws were proposed frequently. By slightly tightening the prior for trend growth, we obtained estimates of trend growth that are in line with sample means.

${ }^{8} \mathrm{As}$ reported in the table, our prior for trend growth is a normal distribution with a mean of 0.44 and standard deviation of 0.22. As a comparison, Justiniano et al. (2010) use a similar model and set the prior mean to 0.5 and the standard deviation to 0.03. Thus, our prior is still comparatively loose and well within the ranges used in the literature.

${ }^{9}$ We use the survey conducted in the last month of each quarter and delete any respondent who does not forecast the entire horizon. Further details are presented in the on-line appendix.
} 


\section{Estimation Results}

Our econometric approach jointly estimates the structural parameters and the sequence of expected durations of the zero interest rate policy. In order to assess the convergence properties of the sampler we produced two additional chains and applied the Brooks, Gelman and Rubin diagnostics (Brooks and Gelman (1998) and Gelman and Rubin (1992)), which found no evidence of non-convergence. ${ }^{10}$

\subsection{Structural Parameters}

The mean of the posteriors for the structural parameters are presented in Table 1 and are generally in line with previous findings, which is encouraging for a structural model faced with data from the zero lower bound period. Among the more sizable differences are that monetary policy responds less aggressively to inflation than found by Smets and Wouters (2007) $\left(\psi_{1}\right.$ is 1.62, compared with 2.04) and the price Phillips curve is flatter (the Calvo parameter, $\xi_{p}$, is 0.91 , considerably higher than their estimate of 0.66). The preferences of the representative household also exhibits some differences, with external habits less important ( $h$ is 0.44 , down from 0.71 ), and the elasticity of labor supply smaller (1.33, compared to 1.83$)$.

Turning to the shock processes, the most notable differences are that the estimated persistence of the risk-premium shock has substantially increased $\left(\rho_{b}\right.$ is 0.95 , whereas Smets and Wouters $(2007)$ found 0.22 ), and the persistence of the monetary policy shock has also increased ( $\rho_{m}$ is 0.43 , compared with $0.15) .{ }^{11}$

\subsection{Expected Durations}

The mean prior and posterior of the expected durations are summarized in Figure $3 .{ }^{12}$ There is considerable variation in the posterior mean over the zero lower bound period; initially it is reasonably short - around one year - whereas by 2012 it reaches as long as 3 years.

Several aspects of the posterior are of note. First, as the prior is an average of the survey and uniform prior, in 2009 its mean is around 2 years, whereas the posterior mean is shorter, 1 year or less, and in-line with the survey data. Second, the standard deviation of the posterior is considerably smaller than that of the prior. Additional results presented in the on-line appendix show that these estimates are robust to varying the weight on the survey data in the prior. This suggests that the expected durations are well identified.

Another noteworthy aspect of the posterior is the shift in the expected durations associated with the adoption of calendar-based forward guidance in August 2011. Figure 4 shows the marginal distributions of the expected durations throughout 2011. As reported in Figure 3, the posterior mean of the expected duration increases by more than the prior mean in 2011Q3. This appears to be due to a shift in the bulk of posterior mass from being less than two years to being more than two years. In the first two quarters, the posterior is consistent with the underlying survey data, with the data placing little or no weight on longer durations. In the last two quarters, however, the posterior places more mass between 2-4 years, suggesting that the macroeconomic data and model support longer durations than the survey data. Even for the period prior to the adoption of calendar-based forward guidance the marginal distributions are reasonably non-normal with relatively long right-hand tail skew. Bauer and Rudebusch (2016) find similar shapes and note that "...the distribution is very strongly skewed to the right - even very distant horizons for policy liftoff are not uncommon" (p. 15).

Other authors have used different models and data to estimate expected durations. For example, Swanson and Williams (2014) construct estimates of the probability of the federal funds rate being less than 50 basis points in five quarters time from options data, and from August 2011 onwards these fluctuate around 85 per cent. Before this the probability is substantially lower, although throughout

\footnotetext{
${ }^{10}$ Chains have 2 million draws, with the first half discarded as a burn-in. Shorter chains of 1 million draws also pass these diagnostics. See the on-line appendix for the corrected scale reduction factors.

${ }^{11}$ See the online appendix for estimates of the structural parameters on the sub-sample pre-ZLB and for variance decompositions for long-term rates

${ }^{12}$ See the online appendix for additional results summarizing the posterior and prior distributions of the expected durations.
} 
much of 2010 it is around 60 and begins to increase from the June quarter of 2011. Krippner (2014) extracts the expected duration from a two-state variable shadow yield curve model and obtains estimates that are strongly correlated with ours, although they are somewhat shorter in 2009. ${ }^{13}$ Broadly similar estimates, albeit a little shorter during the calendar-based forward guidance period, are obtained from a shadow yield curve model and one augmented with macro factors by Bauer and Rudebusch (2016). Meanwhile, these results are inconsistent with a constant expected duration, as would be implied by construction by a two-state Markov-switching model.

\section{Monetary Policy at the Zero Lower Bound}

In this section, we analyze monetary policy at the zero lower bound (ZLB). First, the estimated model is used to quantify the extent to which the ZLB represented a constraint on monetary policy after 2009 by looking at implied shadow rates. Second, we assess the real costs of the ZLB constraint in terms of forgone output. Third, the joint posterior for the model is used to study forecasts conditional on expected duration. Fourth, we conduct impulse response analysis to measure the impact of an exogenous change in the expected duration on macroeconomic aggregates. Although models of the term structure, like those of Bauer and Rudebusch (2016) and Krippner (2015), can be used to produce estimates of the expected duration, these are not structural models that link monetary policy to the aggregate economy. As such, they cannot be used to answer the type of questions posed in this section.

\subsection{Has the ZLB represented a constraint?}

We construct two measures of the shadow rate, neither of which feed back into the rest of the model. The first measure, $r_{t}^{u}$, is defined by

$$
r_{t}^{u} \equiv \rho_{R} r_{t-1}^{u}+\left(1-\rho_{R}\right)\left(\psi_{1} \pi_{t}+\psi_{2}\left(y_{t}-y_{t}^{f}\right)\right)+\psi_{3}\left(\Delta y_{t}-\Delta y_{t}^{f}\right),
$$

which is the interest rate that would have prevailed if the central bank followed its rule absent the zero lower bound. We refer to $r_{t}^{u}$ as the unconditional shadow rate as it does not depend on the ZLB in any way. The second, $r_{t}^{c}$, is defined by,

$$
r_{t}^{c} \equiv \rho_{R} r_{t-1}^{o b s}+\left(1-\rho_{R}\right)\left(\psi_{1} \pi_{t}+\psi_{2}\left(y_{t}-y_{t}^{f}\right)\right)+\psi_{3}\left(\Delta y_{t}-\Delta y_{t}^{f}\right),
$$

which we refer to as the conditional shadow rate, as it depends on the ZLB for determining the previous rate, but not the current one.

The two definitions differ in terms of the lagged interest rate that enters the rule. Notice that the estimate of the flexible-price level of output is the same for both measures. It is the latter, $r_{t}^{c}$, which determines if the zero lower bound is binding at $t$. This is because at the time of liftoff, as the Taylor rule takes over, it is $r_{t-1}^{o b s}$ that matters in determining $r_{t}^{o b s}$. If $r_{t}^{c}<0$ then the zero lower bound binds; the magnitude of $r_{t}^{c}$ can be thought to measure the tightness or slack of the constraint. The unconditional shadow rate, $r_{t}^{u}$, provides a different counterfactual metric which is useful because it reveals what conventional policy would have implied given the same fundamentals but absent any constraint on interest rates.

Figure 5 plots the posterior distribution for both shadow rates. The distribution reflects uncertainty stemming both from the shocks and parameters. The mean of the posterior of $r_{t}^{c}$ is negative in every quarter since 2009 which suggests that the ZLB has indeed represented a constraint. Considering the entire posterior distribution, the ZLB has been a constraint with close to probability one for 17 quarters of the 22 quarters of the ZLB subsample. Although there is non-negligible probability (between 15 and 20 per cent) that the ZLB was not a constraint in five quarter since 2009, the slack in the constraint is estimated to be quantitatively small. For example, for 2012Q1, the probability that $r_{t}^{c}>0$ is 18.9 per cent, but the average value of $r_{t}^{c}$ over that range is only 7 basis points.

\footnotetext{
${ }^{13}$ This approach is summarized in Krippner (2015). The on-line appendix compares our results to his.
} 
The shadow rates, especially the unconditional one, are persistently negative in part because inflation has been persistently below target but mostly because the output gap has been large (as much as -10 per cent) and persistently negative since the onset of the zero interest rate policy, which reflects the failure of average hours worked to recover - an observed variable in estimation - despite falls in the unemployment rate. ${ }^{14}$

Krippner (2011), Wu and Xia (2016) and Bauer and Rudebusch (2016) propose a different concept for the shadow rate. Their approach models the option value of holding cash when the interest rate is zero, which can be subtracted from the observed yields. This shadow rate is intended to measure the stance of monetary policy - i.e., to capture the impact that unconventional policies have on the economy when the actual policy rate is zero. A negative shadow rate is an 'as-if' measure of the monetary policy stance; that is, a set of unconventional policies equivalent in their effects to the hypothetical that the Federal Reserve would have been able to set a negative interest rate. Our shadow rates, by contrast, represent what the Federal Reserve would have done according to its estimated policy rule in the absence of the constraint, $r_{t}^{u}$, or the extent to which the constraint is binding or slack, $r_{t}^{c}$. Meanwhile, our structural model allows a direct analysis of the effects of unconventional policy, as considered below.

\subsection{Quantifying the Severity of the ZLB Constraint}

The above analysis reveals that the ZLB has been an important constraint in the United States. If possible, given the state of the economy, the Federal Reserve would have set a negative interest rate. To measure the macroeconomic implications, we ask, how the economy would have evolved, given the same estimated shocks, but absent the ZLB constraint?

To construct these counterfactuals histories, we proceed as follows: First, we take the mode of the posterior of the structural parameters and the sequence of expected durations and compute estimates of the structural shocks using the Kalman smoother. Then, paths for the observed variables are computed for the entire sample using these shocks together with pre-2009 model solution matrices. The results are displayed in Figure 6.

The differences in the growth rates for many of the variables are often small, but nonetheless imply significant and persistent differences in the evolution of the levels, which are plotted in Figure 6 . With the exception of the interest rates, the levels are normalized to 100 in 2008Q4. Our estimates suggest that, as one would expect, had monetary policy been able to set lower interest rates, output, consumption, investment, employment, real wages and the price level would have been higher and longer maturity yields lower. Relative to this counterfactual, we find that the 22 quarters of zero interest rates imply a cumulative loss of output of 45.3 per cent, 45.2 per cent for consumption and 97.9 per cent for investment. The effect on yields is also substantial; the 5 -year rate, for example, is around 1.5 percentage points lower. The difference in inflation is much more modest as evidenced by the evolution of the price level. This result that relaxing the ZLB constraint has a larger impact on output than on inflation is consistent with the significant spike of the risk premium process post 2009 given the analysis of Del Negro et al. (2015), who show that a version of the Smets Wouters model with financial frictions predicts a sharp contraction in economic activity along with a protracted but relatively small decline in inflation following a jump in financial stress. Thus, the impact of relaxing the ZLB constraint is not independent of which shocks are driving fluctuations.

The negative federal funds rate in this counterfactual is higher than the unconditional shadow rate, $r_{t}^{u}$, in Figure 5. This is to be expected. That shadow rate is the level according to the Taylor rule, given the output gap and inflation. But the output gap and inflation were determined by the rate set by the Federal Reserve - i.e., the zero interest rate. In the counterfactual here, however, the negative interest rate in Figure 6 is the interest rate that determines inflation and the output gap, that is, when the ZLB constraint is not imposed.

Consistent with results of Gust et al. (Forthcoming), we find that the zero lower bound placed a significant constraint on monetary policy, exacerbated the recession and delayed the recovery.

\footnotetext{
${ }^{14}$ The on-line appendix contains estimates of the output gap and structural shocks. Notably the estimated output gap closely resembles the path of hours worked.
} 


\subsection{Conditional forecasts at the $Z L B$}

Next, we probe deeper into the relation between the risk premium process and the expected duration of the zero interest rate policy by considering forecasts conditional on an expected duration. For illustration, we consider a forecast after 2011Q2, the quarter in which the Federal Reserve made its first calendar-based announcement and the expected duration is estimated to have increased. To investigate the effect of expected duration on the conditional forecasts, two very different scenarios are considered. In particular, Figure 7 compares the forecasts obtained with an expected duration of 4 quarters with those obtained when the expected duration is 16 quarters. ${ }^{15}$ In each case the duration is assumed to decrease in the forecast horizon by 1 quarter in every quarter until the Taylor rule takes over.

The forecasts are constructed using the joint posterior distribution for the whole model. Consequently, different draws of an expected duration also correspond to different draws of the structural parameters. In particular, draws for which the expected duration is 16 are also draws where the variance of the risk premium shock is larger and its persistence smaller. At the mean of these draws, the standard deviation of the risk premium shock is 0.058 at duration 4 and 0.064 at duration is 16 . This is important because the size of the shocks determine the state of the risk premium process, $\hat{b}_{t}$, and this process can work to amplify or mute the impact that a given expected duration has on the economy.

To see this consider how the expected duration interacts with $\hat{b}_{t}$ in the Smets Wouters model. For this purpose take the equation for consumption,

$$
\hat{c}_{t}=c_{1} \hat{c}_{t-1}+\left(1-c_{1}\right) \mathbb{E}_{t} \hat{c}_{t+1}+c_{2}\left(\hat{l}_{t}-\mathbb{E}_{t} \hat{l}_{t+1}\right)-c_{3}\left(\hat{r}_{t}-\mathbb{E}_{t} \hat{\pi}_{t+1}-\hat{b}_{t}\right),
$$

and the equation for the price of investment,

$$
\hat{q}_{t}=q_{1} \mathbb{E}_{t} \hat{q}_{t+1}+\left(1-q_{1}\right) \mathbb{E}_{t} \hat{r}_{t+1}^{k}-\left(\hat{r}_{t}-\mathbb{E}_{t} \hat{\pi}_{t+1}-\hat{b}_{t}\right) .
$$

These are the two equations where the risk premium shock, $\hat{b}_{t}$, enters and, with the exception of the monetary policy rule, the two equations where the policy rate enters. The last term on the right hand side of these expressions, $\left(\hat{r}_{t}-\mathbb{E}_{t} \hat{\pi}_{t+1}-\hat{b}_{t}\right)$, makes clear why the impact of the expected duration depends on the nature of the risk premium shock. A large, negative and persistent $\hat{b}_{t}$ offsets the potentially expansionary impact of the expected duration. But a small, positive and persistent $\hat{b}_{t}$ can in fact amplify the expansionary impact of the expected duration. This explains why one may find large estimates of the expected duration which do not give rise to implausibly large responses of aggregate variables, counter to the 'forward guidance puzzle' phenomenon identified by Carlstrom et al. (2015) and Del Negro et al. (2012). Thus, our findings are in line with those of De Graeve et al. (2014) who show that models of this kind can generate realistic effects of forward guidance policies when they are specified conditional on the state of economy.

Related, forecasts conditional on different expected durations may be quite different. In Figure 7, a more negative state of $\hat{b}_{t}$ is associated with the longer expected duration of 16 quarters. However, the combination of the state of the risk premium shock and the expected duration is such that an expected duration of 16 quarters leads to a major shift in the projected timing of recovery than an expected duration of 4 quarters in 2011Q3. In particular, output, consumption, investment and hours are projected to recover faster, although by the time of expected liftoff in the 16 quarters scenario, monetary policy faces a stronger economy and so the policy rate increases faster than is projected in the 4 quarters scenario. This explains why the conditional forecasts cross by the time of liftoff in the 16 quarters scenario.

These conditional forecasts suggest that a longer expected duration brings forward higher output growth in the near term, with lower offsetting growth at longer horizons. This pattern is repeated for all the real variables. A longer expected duration also corresponds to a lower path for long-term interest rates. Meanwhile, expected duration has less impact on the conditional forecast of inflation. However, these are forecasts only and do not necessarily reflect the causal effects of expected duration. To examine causal effects, it is necessary to consider impulse response analysis, which we do next.

\footnotetext{
${ }^{15}$ Figure 7 shows the mean of the posterior along with the $10^{t h}$ to $90^{t h}$ percentiles.
} 


\subsection{The Effect of a Change in the Expected Duration}

An advantage of using a structural model is that it allows us to measure the impact on macroeconomic aggregates of an exogenous change in the expected duration of the zero interest rate policy. Because the solution over the fixed-rate regime is non-linear, it is important to use conditional generalized impulse responses, as proposed by Koop et al. (1996). In principle, one can average the impact of a change in duration over different magnitudes, signs, quarters in which it occurs and even different histories. But we find, in keeping with how such inference might be used in practice, impulse responses conditional on the history of the observed variables and on a given magnitude and direction to be the most informative.

In particular, we choose the 2013Q2 quarter, which coincides with a large fall in the expected duration. This quarter corresponds to the so-called 'Taper tantrum', with an increase in bond yields following the Federal Reserve's surprising announcement that it would start slowing the pace of its bond purchases. Although the Federal Reserve probably did not intend changes to its balance sheet policies to imply changes in the expected duration of the zero interest rate policy, this appears to have been how it was interpreted. The posterior estimates (at the mode) reveal a fall in expected duration of 6 quarters, falling from 11 quarters in 2013Q1 to 5 quarters in 2013Q2.

Computation of the generalized impulse responses proceeds as follows. First, select a quarter of the fixed-rate regime, in this case 2013Q2. Then select a base duration, in this case 10 quarters, which is what would be expected given that the expected duration was 11 quarters in 2013Q1. We then take draws from the joint posterior and keep only those draws for which the duration is 10 quarters in 2013Q2. For each draw, run the Kalman smoother to obtain estimates of the shocks and initial states and construct base forecasts as done above; that is, forecasts where the duration decreases by 1 quarter in every quarter until the Taylor rule takes over. We then construct counterfactual sequences of expected durations which subtracts for each draw 5 quarters to the base duration in 2013Q2. Specifically, for 2013Q2, the base duration of 10 quarters is replaced with the alternative duration of 5 quarters. Using the shocks and initial states computed at the base, we construct the alternative forecasts using the counterfactual sequence of durations. The impulse response to a fall in the duration is computed as the difference between the alternative path and the base path.

Figure 8 shows the difference for each draw and the mean difference in blue. A fall in the duration of 5 quarters corresponds to a significant contractionary monetary policy. It implies an increase in the expected path of the federal funds rate relative to what it would have been otherwise after liftoff. The average cumulative difference in the interest rate paths amounts to 292 basis points. Notice that this corresponds to an anticipated path shock as the federal funds rate is unresponsive until liftoff under the counterfactual, but the rest of the variables respond on impact. The higher expected path of the federal funds rate increases the 5 -year rate by around 10 basis points. This estimate is in line with the observed impact of the ten-year rate at the time of the announcement, $12 \mathrm{pm}$ on the 19th of June. The fall in inflation is relatively small, so the increase in interest rates leads to increases in the real cost of borrowing, which in turn leads to consumption and investment being more expensive and consequently leads to initial declines in consumption and investment growth. The fall in real activity in turn leads to a prolonged fall in hours worked.

Consistent with the conditional forecasts, we find that an exogenous change in expected duration has significant effects on the real economy, but less so on inflation, with a decrease in expected duration being highly contractionary in the near term. The result that the response of inflation is modest is consistent with the large increase that detected in the risk premium process post 2009. In fact, Del Negro et al. (2015) also find that the response to an increase in financial stress is a sharp contraction in real activity along with a modest decline in inflation. As Smets and Wouters (2007) argue, the risk premium shock can be interpreted as a net worth shock thought to stem from the financial system, as in financial accelerator models along the lines of Bernanke et al. (1999).

\section{Conclusions}

The Great Recession has had important implications for monetary policy. Facing the lower bound on nominal interest rates, many central banks, including the Federal Reserve, have engaged in other policies such as forward guidance in an attempt to stimulate the economy. 
Our main contribution is to propose a relatively simple and numerically tractable way to estimate structural models with forward-looking expectations over samples that have a long spell of fixed interest rates. Our approach builds on Kulish and Pagan (2017) and jointly estimates the structural parameters and the expected duration of the zero interest rate policy in each quarter of the regime. We apply the method to a version of the workhorse Smets and Wouters (2007) model of the United States economy augmented with a yield curve, drawing upon Graeve et al. (2009). Our estimates suggests that the structural parameters are encouragingly robust when faced with data from the zero lower bound period and that the expected duration of the zero interest rate policy has varied considerably over time, increasing substantially with the adoption of calendar-based forward guidance in 2011 and decreasing dramatically with the so-called 'Taper tantrum' in 2013. ${ }^{16}$ Our estimates of the expected durations are in line both with yield-curve models (Krippner (2014)) and survey based estimates. We also find, like Bauer and Rudebusch (2016), non-negligible probabilities in every quarter on relatively long durations, 4 years or so.

In the alternative occasionally binding constraint approach of Guerrieri and Iacoviello (2015) and Jones (2015), the expected duration is only a function of past and present shocks. Here, the sequence of expected durations are treated as additional parameters in estimation. Doing so implies that the estimated expected duration can exceed or fall short of the expected duration implied by the constraint. This is desirable if the fixed interest rate policy is intended to continue after the constraint is no longer binding (i.e., the policy rate is held "lower for longer") or if the fixed interest rate policy is implemented at a level different to that of the constraint. But an extension that penalizes draws for which the sequence of expected durations imply violations of the constraint (in the forecasts) when the fixed-rate regime ends is a worthwhile task that we leave for future research.

\section{References}

An, S., Schorfheide, F., 2007. Bayesian Analysis of DSGE Models. Econometrics Reviews 26 (2-4), $113-172$.

Baele, L., Bekaert, G., Cho, S., Inghelbrecht, K., Moreno, A., 2015. Macroeconomic regimes. Journal of Monetary Economics 70, 51-71.

Bauer, M. D., Rudebusch, G. D., October 2016. Monetary Policy Expectations at the Zero Lower Bound. Journal of Money, Credit and Banking 48 (7), 1439-1465.

Bernanke, B. S., Gertler, M., Gilchrist, S., 1999. The Financial Accelerator in a Quantitative Business Cycle Framework. Elsevier Science, Amsterdam, pp. 1341-1393.

Bianchi, F., Melosi, L., April 2017. Escaping the Great Recession. American Economic Review 107 (4), $103-58$.

Binder, M., Pesaran, M. H., 1995. Multivariate Rational Expectations Models and Macroeconometric Modelling: A Review and Some New Results. In: in M Hashem Pesaran, Wickens, M. (Eds.), Handbook of Applied Econometrics: Macroeconomics. Basil Blackwell, Oxford, pp. 139-187.

Binning, A., Maih, J., 2016. Implementing the zero lower bound in an estimated regime-switching dsge model. Working Paper 03-2016, Norges Bank.

Boneva, L. M., Braun, R. A., Waki, Y., 2016. Some Unpleasant Properties of Loglinearized Solutions when the Nominal Rate is Zero. Journal of Monetary Economics 84 (C), 216-232.

Brooks, S., Gelman, A., 1998. General Methods for Monitoring Convergence of Iterative Simulations. Journal of Computational and Graphical Statistics 7 (4), 434-455.

Cagliarini, A., Kulish, M., 2013. Solving Linear Rational Expectations Models with Predictable Structural Changes. Review of Economics and Statistics 95, 328-336.

\footnotetext{
${ }^{16}$ See the on-line appendix for a comparison with the pre-2009 sample estimates.
} 
Campbell, J. Y., Shiller, R. J., 1991. Yield Spreads and Interest Rate Movements: A Bird's Eye View. Review of Economic Studies 58 (3), 496-514.

Carlstrom, C. T., Fuerst, T. S., Paustian, M., 2015. Inflation and output in new keynesian models with a transient interest rate peg. Journal of Monetary Economics 76, 230-243.

Chen, H., 2014. Assessing the Effects of the Zero-Interest-Rate Policy through the Lens of a RegimeSwitching DSGE Model. Working Paper 2014-38, Federal Reserve Board.

Chib, S., Ramamurthy, S., March 2010. Tailored Randomized Block MCMC Methods with Application to DSGE Models. Journal of Econometrics 155 (1), 19-38.

De Graeve, F., Ilbas, P., Wouters, R., 2014. Forward guidance and long term interest rates: inspecting the mechanism. Working Paper 292, Sveriges Riksbank.

Del Negro, M., Giannoni, M., Patterson, C., 2012. The Forward Guidance Puzzle. Staff Reports 574, Federal Reserve Bank of New York.

Del Negro, M., Giannoni, M., Schorfheide, F., 2015. Inflation in the great recession and new keynesian models. American Economic Journal: Macroeconomics 7 (1), 168-196.

Ding, P., 2016. On the Conditional Distribution of the Multivariate t Distribution. The American Statistician 70 (3), 293-295.

Eggertsson, G., Woodford, M., 2003. Zero Bound on Interest Rates and Optimal Monetary Policy. Brookings Papers on Economic Activity 1, 139-233.

Fernández-Villaverde, J., Gordon, G., Guerrón-Quintana, P., Rubio-Ramirez, J. F., 2015. Nonlinear adventures at the zero lower bound. Journal of Economic Dynamics and Control 57, 182-204.

Gelman, A., Rubin, D., 1992. Inference from Iterative Simulation Using Multiple Sequences. Statistical Science 7, 457-511.

Graeve, F. D., Emiris, M., Wouters, R., 2009. A Structural Decomposition of the US Yield Curve. Journal of Monetary Economics 56, 545-559.

Guerrieri, L., Iacoviello, M., March 2015. Occbin: A Toolkit to Solve Models with Occasionally Binding Constraints Easily. Journal of Monetary Economics 70, 22-38.

Gust, C. J., Herbst, E. P., Lopez-Salido, D., Smith, M. E., Forthcoming. The Empirical Implications of the Interest-Rate Lower Bound. American Economic Review.

Jones, C., 2015. Unanticipated Shocks and Forward Guidance at the Zero Lower Bound. Mimeograph, New York University.

Jung, T., Teranishi, Y., Watanabe, T., 2005. Optimal Monetary Policy at the Zero-Interest Rate Bound. Journal of Money, Credit and Banking 37, 813-835.

Justiniano, A., Primiceri, G. E., Tambalotti, A., 2010. Investment shocks and business cycles. Journal of Monetary Economics 57 (2), 132-145.

Koop, G., Pesaran, M. H., Potter, S. M., 1996. Impulse response analysis in nonlinear multivariate models. Journal of Econometrics 74 (1), 119-147.

Krippner, L., 2011. Modifying Gaussian Term Structure Models when Interest Rates Are Near the Zero Lower Bound. Discussion Paper 36/2011, Centre for Applied Macroeconomic Analysis, Australian National University.

Krippner, L., 2014. Measures of the Stance of United States Monetary Policy. Accessed 24 November 2014.

URL http://www.rbnz.govt.nz/research_and_publications/research_programme/ additional_research/5655249.html 
Krippner, L., 2015. Zero Lower Bound Term Structure Modelling - A Practitioner's Guide. Palgrave Macmillan.

Kulish, M., Pagan, A., 2017. Estimation and Solution of Models with Expectations and Structural Changes. Journal of Applied Econometrics 32, 255-274.

Rudebusch, G. D., Swanson, E. T., 2008. Examining the bond premium puzzle with a DSGE model. Journal of Monetary Economics 55, 111-126.

Smets, F., Wouters, R., 2007. Shocks and Frictions in US Business Cycles: A Bayesian DSGE Approach. American Economic Review 97, 586-606.

Swanson, E. T., Williams, J. C., 2014. Measuring the Effect of the Zero Lower Bound on Medium- and Longer-Term Interest Rates. American Economic Review 104 (10), 3154-3185.

Werning, I., 2012. Managing a Liquidity Trap: Monetary and Fiscal Policy. Manuscript.

Woodford, M., 2012. Methods of Policy Accommodation at the Interest-Rate Lower Bound. Economic policy symposium, Federal Reserve Bank of Kansas City.

Wu, J. C., Xia, F. D., October 2016. Measuring the Macroeconomic Impact of Monetary Policy at the Zero Lower Bound. Journal of Money, Credit and Banking 48 (7), 1439-1465. 
Table 1: Posterior Estimates of the Smets Wouters (2007) Model

\begin{tabular}{|c|c|c|c|c|c|c|c|c|}
\hline \multicolumn{2}{|l|}{ Parameter } & \multicolumn{3}{|c|}{ Prior } & \multicolumn{4}{|c|}{ Posterior } \\
\hline & & PDF & Mean & Std. Dev. & Mode & Mean & $90 \%$ & HPD \\
\hline \multicolumn{9}{|c|}{ Standard Deviations of the Innovations to the Shocks $\dagger$} \\
\hline Technology & $\sigma_{a}$ & IG & 0.42 & 0.29 & 0.41 & 0.42 & 0.37 & 0.47 \\
\hline Risk premium & $\sigma_{b}$ & IG & 0.20 & 3.00 & 0.06 & 0.06 & 0.05 & 0.07 \\
\hline Fiscal & $\sigma_{g}$ & IG & 0.20 & 3.00 & 0.39 & 0.40 & 0.36 & 0.44 \\
\hline Investment tech. & $\sigma_{q}$ & IG & 0.42 & 0.29 & 0.30 & 0.32 & 0.25 & 0.40 \\
\hline Monetary & $\sigma_{m}$ & IG & 0.20 & 3.00 & 0.11 & 0.11 & 0.10 & 0.13 \\
\hline Price mark-up & $\sigma^{p}$ & $\mathrm{IG}$ & 0.20 & 3.00 & 0.08 & 0.08 & 0.07 & 0.10 \\
\hline Wage mark-up & $\sigma^{w}$ & $\mathrm{IG}$ & 0.42 & 0.29 & 0.47 & 0.47 & 0.42 & 0.53 \\
\hline Term premia & $\sigma_{\eta}$ & $\mathrm{U}$ & 1.00 & 0.58 & 0.09 & 0.09 & 0.08 & 0.10 \\
\hline 2 year & $\sigma_{8}$ & $\mathrm{U}$ & 1.00 & 0.58 & 0.01 & 0.02 & 0.00 & 0.03 \\
\hline 10 year & $\sigma_{20}$ & $\mathrm{U}$ & 2.50 & 1.44 & 0.09 & 0.09 & 0.08 & 0.11 \\
\hline \multicolumn{9}{|c|}{ Parameters of the Shock Processes } \\
\hline Technology & $\rho_{a}$ & $\mathrm{~B}$ & 0.50 & 0.20 & 0.96 & 0.96 & 0.89 & 0.98 \\
\hline Risk premium & $\rho_{b}$ & $\mathrm{~B}$ & 0.50 & 0.20 & 0.95 & 0.95 & 0.93 & 0.96 \\
\hline Fiscal & $\rho_{g}$ & $\mathrm{~B}$ & 0.50 & 0.20 & 0.97 & 0.97 & 0.95 & 0.99 \\
\hline Investment tech. & $\rho_{q}$ & $\mathrm{~B}$ & 0.50 & 0.20 & 0.70 & 0.70 & 0.56 & 0.79 \\
\hline Monetary & $\rho_{m}$ & $\mathrm{~B}$ & 0.50 & 0.20 & 0.43 & 0.43 & 0.32 & 0.52 \\
\hline Price mark-up & $\rho_{p}$ & $\mathrm{~B}$ & 0.50 & 0.20 & 0.89 & 0.89 & 0.77 & 0.92 \\
\hline Wage mark-up & $\rho_{w}$ & $\mathrm{~B}$ & 0.50 & 0.20 & 0.99 & 0.99 & 0.98 & 0.99 \\
\hline Term premia & $\rho_{s}$ & $\mathrm{~B}$ & 0.71 & 0.16 & 0.81 & 0.81 & 0.72 & 0.89 \\
\hline MA price mark-up & $\mu_{p}$ & $\mathrm{~B}$ & 0.50 & 0.20 & 0.82 & 0.79 & 0.64 & 0.88 \\
\hline MA wage mark-up & $\mu_{w}$ & $\mathrm{~B}$ & 0.50 & 0.20 & 0.97 & 0.97 & 0.96 & 0.98 \\
\hline Fiscal technology & $\rho_{g a}$ & $\mathrm{~N}$ & 0.50 & 0.25 & 0.44 & 0.44 & 0.29 & 0.57 \\
\hline \multicolumn{9}{|l|}{ Structural Parameters } \\
\hline Inv. adj. costs & $\varphi$ & $\mathrm{N}$ & 4.00 & 1.50 & 5.79 & 5.89 & 4.23 & 7.80 \\
\hline IES & $\sigma_{c}$ & $\mathrm{~N}$ & 1.50 & 0.38 & 1.05 & 1.06 & 0.87 & 1.27 \\
\hline Habits & $h$ & B & 0.70 & 0.10 & 0.44 & 0.44 & 0.35 & 0.54 \\
\hline Wage Calvo & $\xi_{w}$ & $\mathrm{~B}$ & 0.50 & 0.10 & 0.73 & 0.73 & 0.68 & 0.77 \\
\hline Labour supply & $\sigma_{l}$ & $\mathrm{~N}$ & 2.00 & 0.75 & 1.24 & 1.33 & 0.78 & 1.94 \\
\hline Price Calvo & $\xi_{p}$ & $\mathrm{~B}$ & 0.50 & 0.10 & 0.91 & 0.91 & 0.88 & 0.93 \\
\hline Indexation wages & $\iota_{w}$ & $\mathrm{~B}$ & 0.50 & 0.15 & 0.43 & 0.47 & 0.24 & 0.73 \\
\hline Indexation prices & $\iota_{p}$ & $\mathrm{~B}$ & 0.50 & 0.15 & 0.16 & 0.17 & 0.07 & 0.30 \\
\hline Capacity utilisation & $\psi$ & $\mathrm{B}$ & 0.50 & 0.15 & 0.83 & 0.72 & 0.70 & 0.92 \\
\hline Fixed cost & $\phi_{p}$ & $\mathrm{~N}$ & 1.25 & 0.13 & 1.40 & 1.41 & 1.28 & 1.56 \\
\hline Mon. policy: Inflation & $\psi_{1}$ & $\mathrm{~N}$ & 1.50 & 0.25 & 1.58 & 1.62 & 1.31 & 1.94 \\
\hline Mon. policy: Smoothing & $\rho_{r}$ & $\mathrm{~B}$ & 0.75 & 0.10 & 0.82 & 0.82 & 0.77 & 0.86 \\
\hline Mon. policy: Gap & $\psi_{2}$ & $\mathrm{~N}$ & 0.13 & 0.05 & 0.14 & 0.14 & 0.10 & 0.19 \\
\hline Mon. policy: Growth & $\psi_{3}$ & $\mathrm{~N}$ & 0.13 & 0.05 & 0.13 & 0.13 & 0.09 & 0.17 \\
\hline ME constant: Inflation & $\bar{\pi}$ & G & 0.63 & 0.10 & 0.53 & 0.56 & 0.43 & 0.71 \\
\hline Discount factor & $\beta^{-1}-1$ & G & 0.25 & 0.10 & 0.13 & 0.14 & 0.23 & 0.60 \\
\hline ME constant: Labour & $\bar{l}$ & $\mathrm{~N}$ & 0.20 & 2.00 & 1.54 & 1.75 & 0.49 & 3.00 \\
\hline Trend growth & $\gamma-1$ & $\mathrm{~N}$ & 0.44 & 0.05 & 0.45 & 0.44 & 0.40 & 0.48 \\
\hline Capital share & $\alpha$ & $\mathrm{N}$ & 0.30 & 0.05 & 0.16 & 0.17 & 0.14 & 0.20 \\
\hline Term premia constant & $c_{8}$ & $\mathrm{~N}$ & 1.20 & 0.25 & 1.23 & 1.24 & 0.94 & 1.53 \\
\hline Term premia constant & $c_{20}$ & $\mathrm{~N}$ & 2.35 & 0.25 & 2.21 & 2.23 & 1.89 & 2.56 \\
\hline \multicolumn{9}{|c|}{$\begin{array}{l}\dagger \text { Moments multiplied by } 10^{-2} \text {. } \\
\text { Abbreviations: PDF: Probability Density Function; HPD: Highest Probability Density; } \\
\text { MA: Moving Average; IES; Intertemporal Elasticity of Substitution; IG: Inverse Gamma; } \\
\text { U: Uniform; B: Beta; G: Gamma; N: Normal. }\end{array}$} \\
\hline
\end{tabular}


Figure 1: Timing of Events

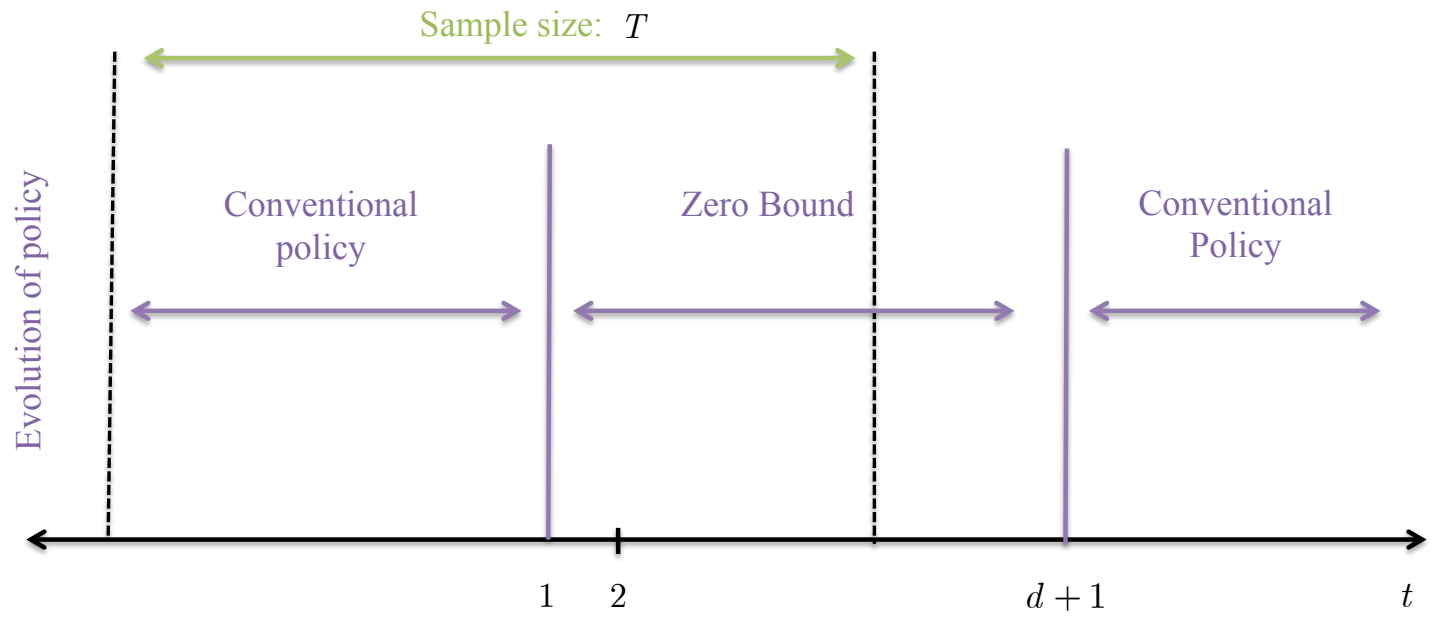


Figure 2: Expected Durations from Survey Data (Percentile)

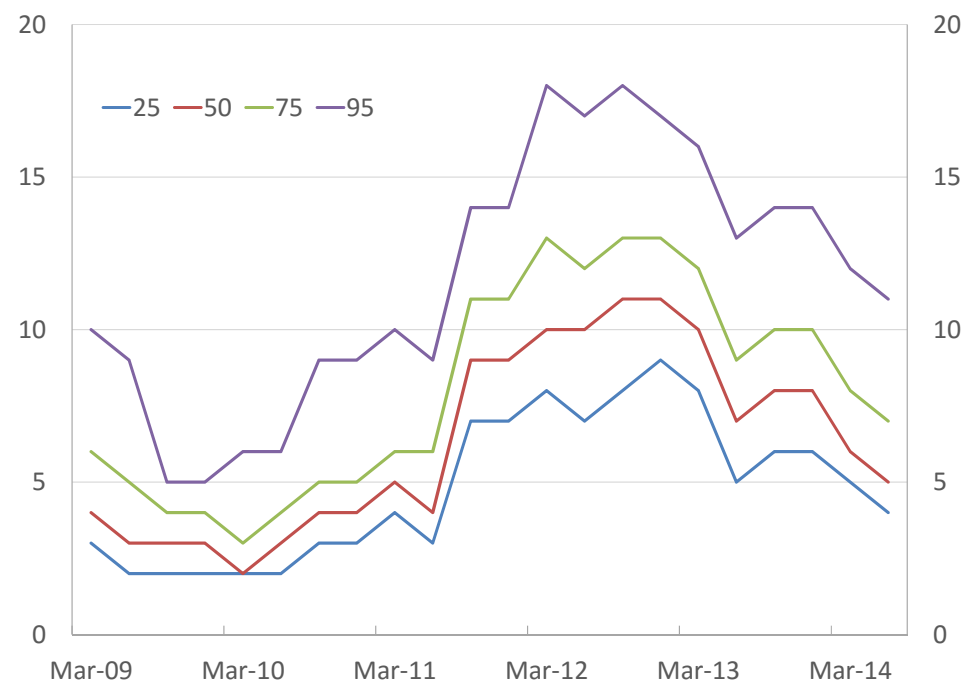


Figure 3: Prior and Posterior Mean Expected Durations

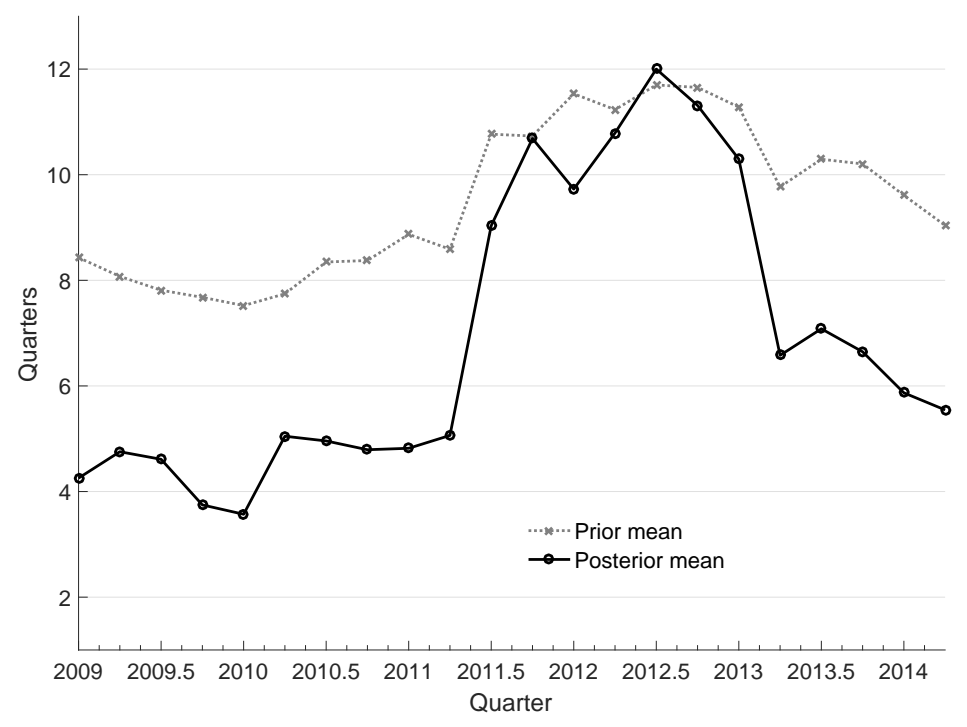


Figure 4: Prior and Posterior Distributions of Expected Durations: 2011
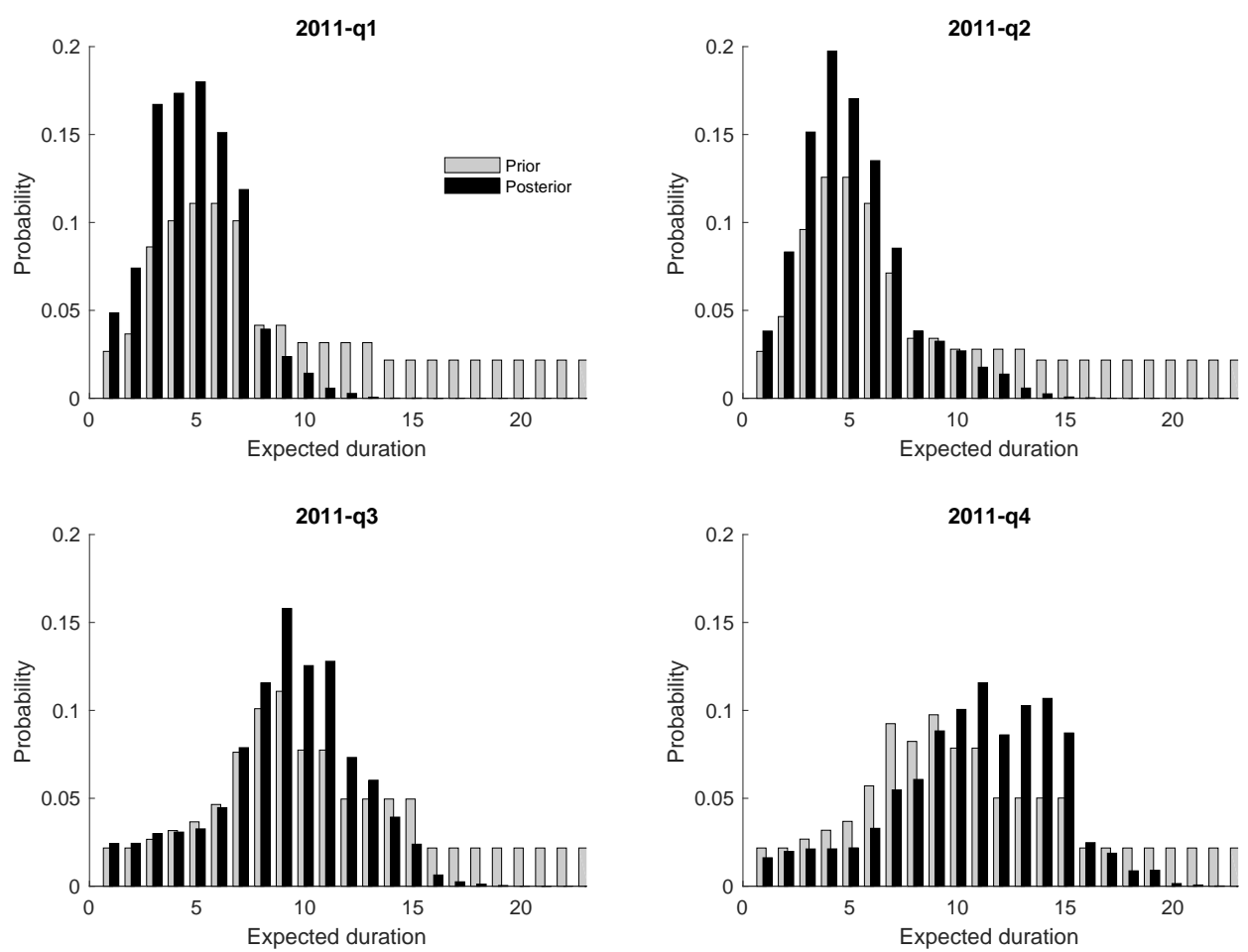
Figure 5: Shadow Rates

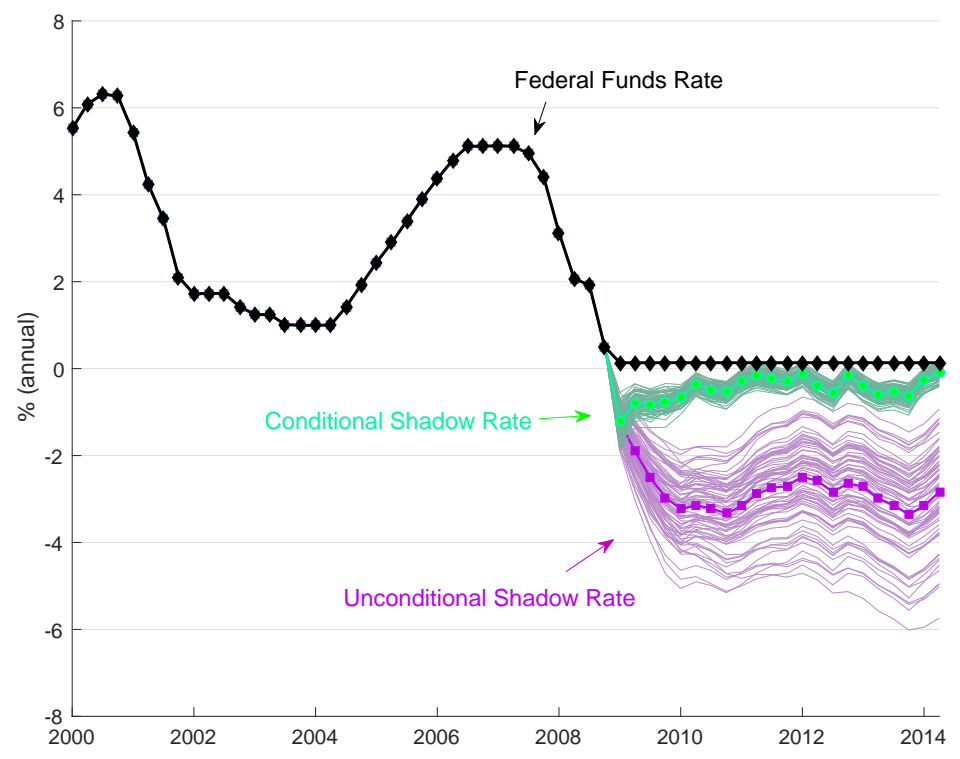


Figure 6: Counterfactual
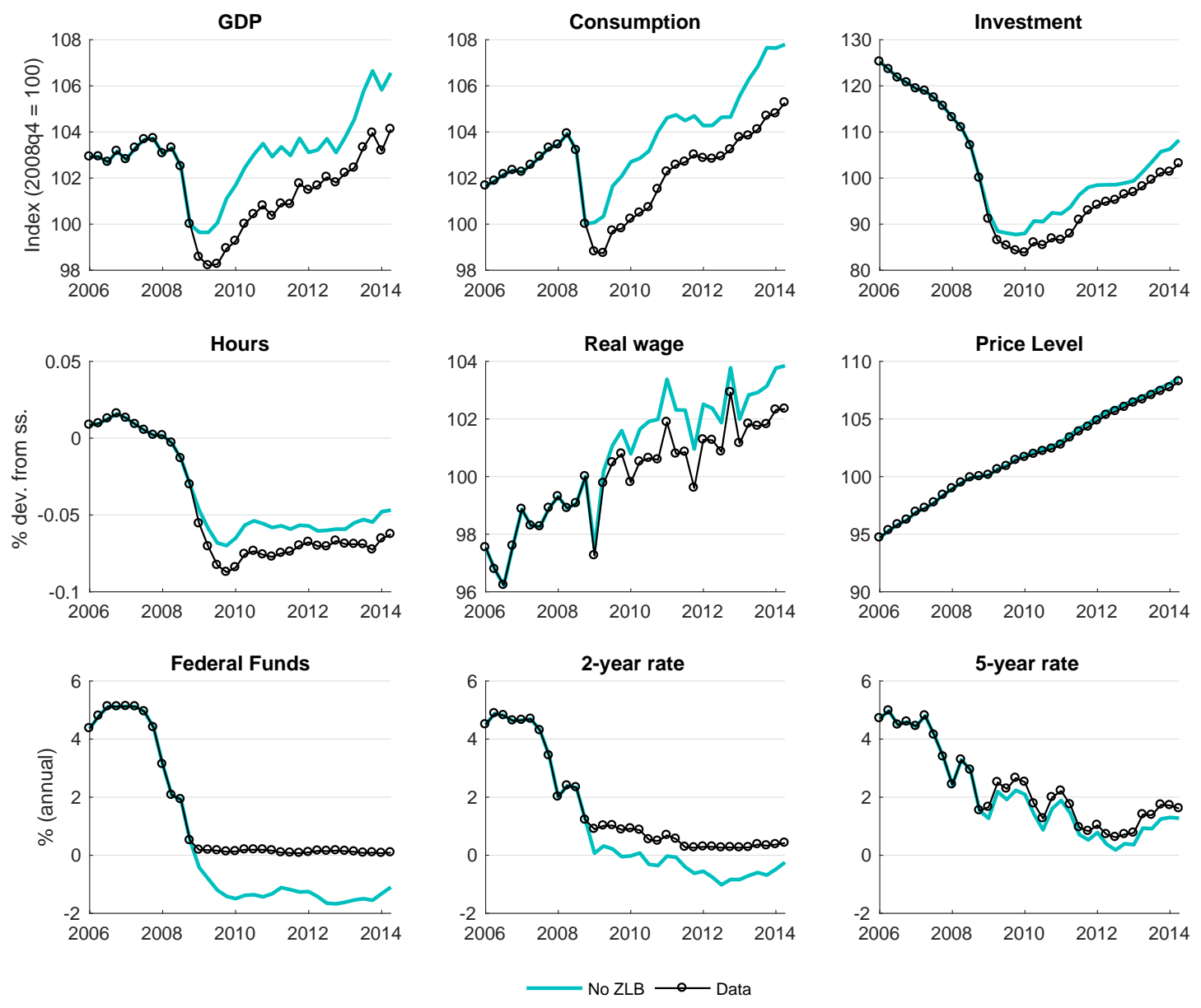
Figure 7: Conditional forecasts: 2011-Q3
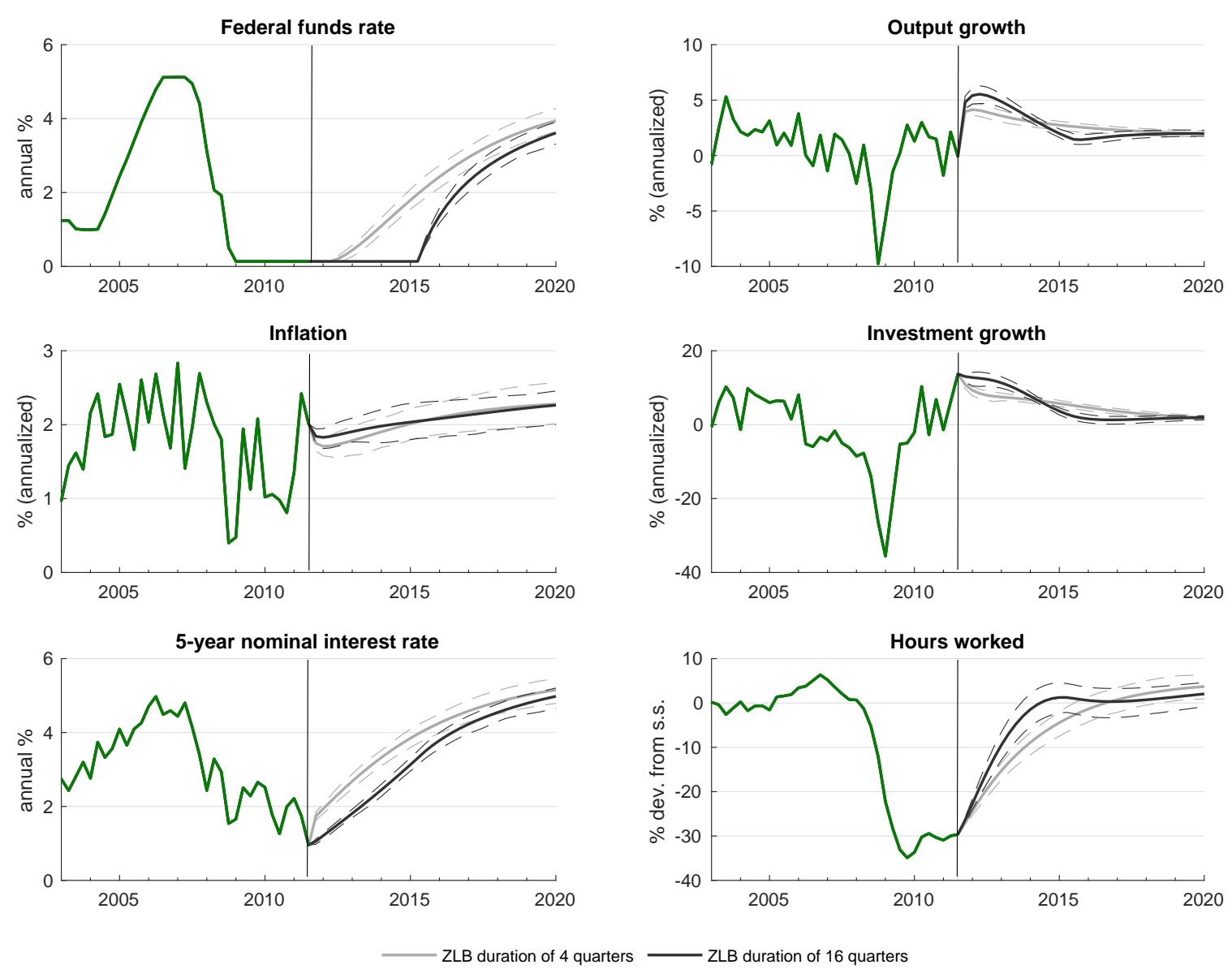
Figure 8: Generalized Impulse Responses: 2013-Q2
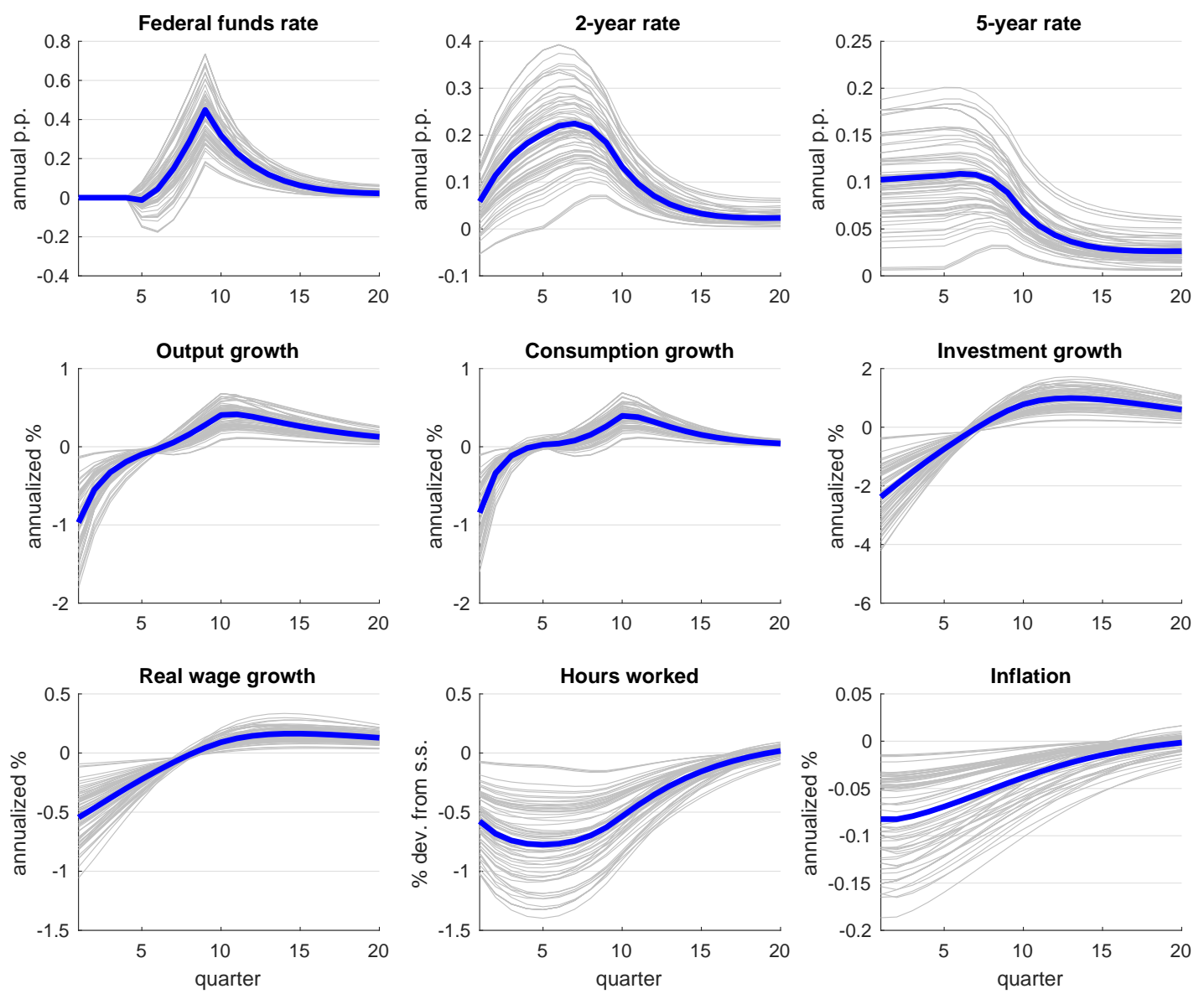